Review

\title{
Intelligent Polymeric Nanocarriers Responding to Physical or Biological Signals: A New Paradigm of Cytosolic Drug Delivery for Tumor Treatment
}

\author{
Bo Reum Lee, Hye Jung Baik, Nam Muk Oh and Eun Seong Lee* \\ Division of Biotechnology, The Catholic University of Korea, 43-1 Yeokgok 2-dong, Wonmi-gu, \\ Bucheon-si, Gyeonggi-do 420-743, Korea
}

* Author to whom correspondence should be addressed; E-Mail: eslee@catholic.ac.kr;

Tel.: +82-2-2164-4921; Fax: +82-2-2164-4865.

Received: 28 April 2010; in revised form: 2 June 2010 / Accepted: 18 June 2010 /

Published: 22 June 2010

\begin{abstract}
The physicochemical properties of stimuli-responsive polymers change with physical or biological signals, such as $\mathrm{pH}$, enzyme concentrations, and temperature. These polymers have attracted considerable attention in the field of drug delivery. The drug carrier system, which was revolutionized by the introduction of these polymers, has recently provided a new paradigm of maximizing the therapeutic activity of drugs. This review highlights recent studies regarding stimuli-responsive drug carriers tailor-made for effective cytosolic drug delivery, with particular emphasis on tumor treatment.
\end{abstract}

Keywords: stimuli-responsive polymer; cytosolic drug delivery; tumor treatment

\section{Introduction}

In general, the targeting of a cytotoxic agent to solid tumors entails the passive accumulation of nano-sized drug carriers around solid tumor tissues, followed by active internalization into tumor cells [1-12]. The cellular internalization of either the drug alone, or with its carrier, is necessary, because the majority of cytotoxic drugs function intracellularly, whereas targeting agents for diagnostic purposes and imaging may not necessarily require internalization [13-15]. 
The passive accumulation of drugs or drug carriers relies heavily on the probability of the extravasation of nano-sized particles through the walls of tumor microvessels. Fortunately, the leaky characteristics of tumor blood vessels, which result from hypervasculature, defective vascular architecture, and a variety of permeability enhancing mediators secreted from tumor cells, are attributed to the enhanced extravasation of a given nano-sized drug carrier into a tumor site from circulation in the blood [12-14]. However, active internalization is generally thought to occur with drug carriers that are directed by a monoclonal antibody (mAb) binding to a tumor associated surface antigen, or by the binding of a ligand to its corresponding receptor on the surface of tumor cells [15-19]. The information in the relevant literature demonstrates that the active targeting of drug carriers with mAbs or ligands results in higher levels of drug accumulation in tumors [20-25]. This active process was expected to result in a remarkable cell killing activity against tumor cells. However, this process does not provide an actual driving force for the effective killing of tumors, because drug carriers localized in vesicles (i.e., endosomes, lysosomes) after endocytosis do not demonstrate vesicular-escaping activity. This activity is needed to selectively elevate drug concentrations in the cytoplasm and nucleus (potential drug acting sites) [20-25].

Recently, nano-sized drug carriers that respond to physical or biological signals, such as $\mathrm{pH}$, temperature, and enzyme expression, have been extensively evaluated for achieving spatial site-specific drug delivery [26-50]. These systems are designed to minimize the rates of drug release into the extracellular space, while maximizing drug concentration in their target site under a particular signal. For example, the acidic $\mathrm{pH}$ in endosomes and specific enzymes can constitute internal signals to facilitate drug transport from endosomes or lysosomes to the cytoplasm. Temperature may also be manipulated as an external signal for the modulation of drug release kinetics for the cytoplasm. It is worth noting that the use of these signals has promoted the creation of a new mode of cytosolic drug/gene delivery system (Figure 1), thus suggesting the potential for a new system of highly sophisticated drug release control [26-59].

Figure 1. Schematic illustration of actions of the stimuli-responsive nanocarriers in the tumor site. Nano-sized drug carriers will be extravasated into tumors and internalized into tumor cells using pinocytosis, receptor-mediated endocytosis, and other internalized mechanisms. The drug release kinetics from nano-sized drug carriers internalized into the cells may be modulated by stimuli, such as $\mathrm{pH}$, enzymes concentrations, and temperatures, to enable effective cytosolic drug delivery.

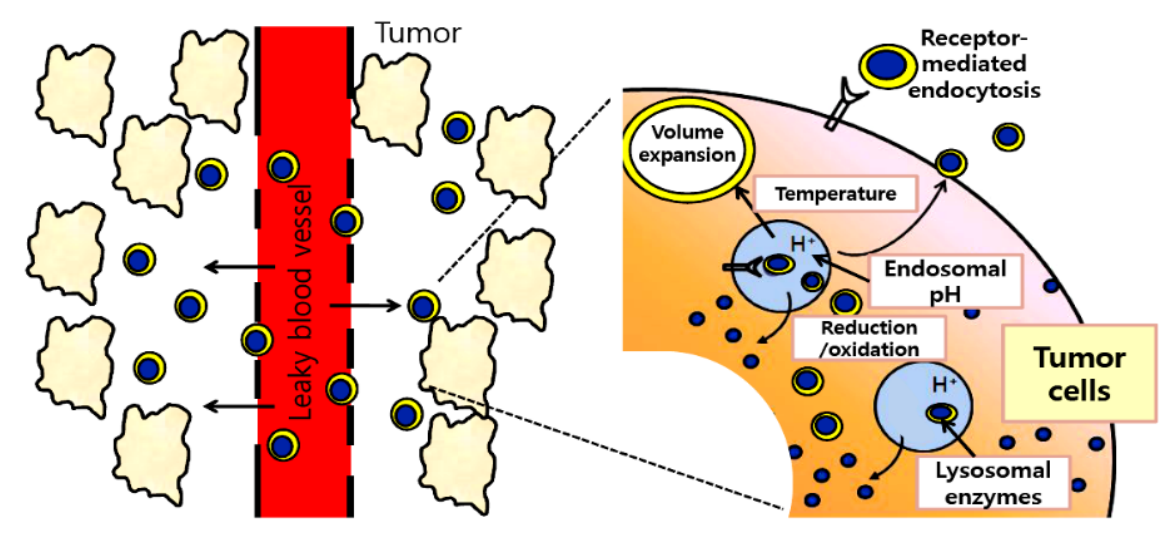


In this review, we summarize and discuss recent representative studies on polymeric drug carriers responding to physical or biological signals for effective cytosolic drug delivery, with a particular emphasis on tumor treatment. However, polymeric carriers for genetic materials, such as plasmid DNA, short-interfering RNA (siRNA), and oligonucleotides (ODN), are not covered here, because a number of review articles regarding cytosolic gene delivery have already been reported.

\section{Stimuli-Responsive Delivery Systems}

\subsection{Acidic $p H$-Activating Systems}

Cellular components, such as cytoplasm, mitochondria, endosomes, lysosomes, and Golgi bodies

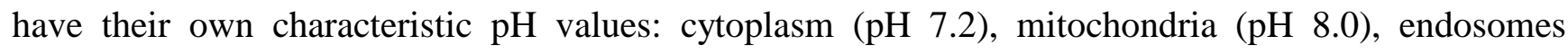
( $\mathrm{pH}$ 5.0-6.0), lysosomes ( $\mathrm{pH}$ 4.0-5.0), and Golgi bodies ( $\mathrm{pH}$ 6.4) [26]. In particular, the more acidic endosomal/lysosomal compartments function as important sites for the pharmaceutical application of $\mathrm{pH}$-responsive polymers as drug carriers (Table 1). After endocytosis, the sequestration of drug carriers in these compartments is ultimately subject to extensive degradation or metabolism in the lysosome. Therefore, the development of drug carriers that respond to endosomal/lysosomal $\mathrm{pH}$ and escape from endosomal compartments will tend to increase the bioavailability of delivered drugs, resulting in avoidance of the sequestration and degradation pathways.

Table 1. Examples of pH-responsive polymers.

\begin{tabular}{|c|c|c|c|}
\hline Polymer & Description & Drug & Ref. \\
\hline PolyHis-b-PEG & $\begin{array}{l}\text { Protonation of the imidazole group in His block } \\
\text { at lower } \mathrm{pH}(\leq \mathrm{pH} 7.2) \text {, resulting drug release }\end{array}$ & DOX & [20] \\
\hline $\begin{array}{l}\text { Blended polymers of polyHis- } b \text {-PEG- } \\
\text { folate /PLLA- } b \text {-PEG-folate }\end{array}$ & $\begin{array}{l}\text { Micelles were destabilized in the } \mathrm{pH} \text { range of } \\
\text { 7.2-6.6, resulting drug release }\end{array}$ & DOX & {$[28,29]$} \\
\hline $\begin{array}{l}\text { Pullulan acetate and oligo- } \\
\text { sulfadimethoxine (PA-g-OSDM) }\end{array}$ & $\begin{array}{l}\text { Acid } \mathrm{pH} \text { induced internal structural change, } \\
\text { resulting drug release }\end{array}$ & DOX & [21] \\
\hline $\begin{array}{l}\text { Poly[( }{ }_{L} \text {-histidine)-co-(c-phenyl } \\
\text { alanine)]-b-PEG (HF-b-PEG) }\end{array}$ & $\begin{array}{l}\text { Drug release by the micelle destabilization at } \\
\text { tumor extracellular } \mathrm{pH}\end{array}$ & DOX & [46] \\
\hline $\begin{array}{l}\text { Poly( } N \text {-isopropylacrylamide) } \\
\text { (PNIPAM) }\end{array}$ & $\begin{array}{l}\text { A coil-to-globule transition at acidic } \mathrm{pH} \text { was } \\
\text { utilized to destabilize intracellular vehicle } \\
\text { membrane }\end{array}$ & DOX & [47] \\
\hline $\begin{array}{l}\text { Folate-PEG-b-poly(aspartate } \\
\text { hydrazone doxorubicin) [Folate-PEG- } \\
b \text { - poly(Asp-Hyd-DOX)] }\end{array}$ & $\begin{array}{l}\text { Hydrazone bond between drug and polymer was } \\
\text { cleaved intracellularly at low } \mathrm{pH} \text { (5.5), resulting } \\
\text { in drug release }\end{array}$ & DOX & [48] \\
\hline $\begin{array}{l}\text { Poly( } \varepsilon \text {-caprolactone-co-lactide)- } b \text { - } \\
\text { PEG-b-poly( } \varepsilon \text {-caprolactone-co- } \\
\text { lactide) with sulfamethazine oligomer } \\
\text { (OSM-PCLA- } b \text {-PEG- } b \text {-PCLA-OSM) }\end{array}$ & $\begin{array}{l}\text { Rapid sol-to-gel transition with change in } \mathrm{pH} \text {, } \\
\text { resulting in triggering drug release }\end{array}$ & PTX & [49] \\
\hline $\begin{array}{l}\text { Poly }(N \text {-isopropylacrylamide- } \\
\text { cobutylmethacrylate-co-acrylic acid) }\end{array}$ & $\begin{array}{l}\text { A pH-dependent drug release behavior was } \\
\text { observed in the } \mathrm{pH} \text { range of } \mathrm{pH} 5.0-6.0\end{array}$ & Insulin & [50] \\
\hline
\end{tabular}


Table 2. Examples of enzymatically responsive polymers.

\begin{tabular}{|c|c|c|c|}
\hline Enzyme-activated polymer & Enzymatic site & Drug & Ref. \\
\hline $\begin{array}{l}N \text {-(2-hydroxypropy1) methacrylamide-GFLG-mesochlorin e6 } \\
\text { (HPMA-GFLG-Mce 6) }\end{array}$ & GFLG & Mce6 & {$[60]$} \\
\hline $\begin{array}{l}N \text {-(2-hydroxypropy1) methacrylamide-GFLG- Geldanamycin } \\
\text { (HPMA-GFLG-GDM) }\end{array}$ & GFLG & GDM & [62] \\
\hline Poly( $\varepsilon$-caprolactone)-b-poly(ethyl ethylene phosphate) & Disulfide bond & DOX & [84] \\
\hline PEG-b-poly(amidoamine) dendrimer- succinic acid-PTX & Ester bond & PTX & [89] \\
\hline Polyglycerol dendrimer- Ala-Phe-Lys-MTX & Ala-Phe-Lys & MTX & [90] \\
\hline Trimeric pro-drug (DOX/CPT/etoposide) & $\begin{array}{l}\text { Aldol, } \\
\text { Retro-aldol }\end{array}$ & $\begin{array}{l}\text { DOX, CPT, } \\
\text { etoposide }\end{array}$ & [91] \\
\hline Poly $(\gamma$-glutamic acid)-based nanoparticles ( $\gamma$-PGA NPs) & $\begin{array}{l}\text { Phenylalanine } \\
\text { ethyl ester }\end{array}$ & OVA & [92] \\
\hline $\begin{array}{l}N \text {-(2-hydroxypropyl) methacrylamide with } \\
\text { methacryloylglycylglycine 4-nitrophenyl ester (PHPMA) }\end{array}$ & Ester bond & $\mathrm{CPT}$ & [63] \\
\hline
\end{tabular}

\subsubsection{Synthetic anticancer drug delivery}

Our group has developed a poly(L-histidine) (polyHis)-based drug carrier system consisting of polyHis- $b$-poly(ethylene glycol)-folate (polyHis- $b$-PEG-folate) and poly(L-lactic acid) (PLLA)- $b$-PEGfolate [27-29], targeted toward effective cytosolic anticancer drug delivery by virtue of the fusogenic activity of polyHis. Herein, the incorporation of a non-ionizable block copolymer (PLLA- $b$-PEGfolate) within the micellar structure of polyHis-b-PEG-folate improved micelle stability at a $\mathrm{pH}$ of 7.4, and shifted micelle destabilization to a lower $\mathrm{pH}$ (i.e., $\mathrm{pH}$ 6.5-6.8), similar to early endosomal $\mathrm{pH}$. The folate, coupled with polyHis- $b$-PEG or PLLA-b-PEG, enabled the efficient cellular uptake of drug carriers for human breast carcinoma MCF-7 cells overexpressing folate receptor (FR). It was noted that drug carriers sequestrated into early endosomes after FR-mediated endocytosis responded to endosomal $\mathrm{pH}$ and released encapsulated anticancer drugs (e.g., doxorubicin: DOX) into the cytoplasm [27-29]. It appeared that the protonation of polyHis at endosomal $\mathrm{pH}$ resulted in the destabilization of the endosomal membrane, which is associated with the proton sponge effect [30]. It has been well established that the vacuolar ATPase $-\mathrm{H}^{+}$pumps in endosomal membranes modulate proton transfer from the cytoplasm to endosomal compartments [30]. If certain materials with protonatable groups are entrapped within these acidic compartments, the transferred protons will be captured by protonatable moieties. This proton buffering leads to a smaller increase in endosomal $\mathrm{pH}$. This causes a simultaneous influx of both protons and their counterions $\left(\mathrm{Cl}^{-}\right)$into the endosomes, thus creating osmotic imbalances between the cytosol and the endosomal compartments. This induces endosomal swelling, as a result of continuous water influx. This ultimately leads to endosomal rupture. Therefore, the polyHis-based drug carrier system effectively carries anticancer drugs to the cytosol of tumor cells, consequently resulting in high cytotoxicity to MCF-7 tumor cells (over 90\%) [27-29].

Bae et al. previously developed a novel intracellular $\mathrm{pH}$-sensitive polymeric micelle with a $\mathrm{pH}$ labile bond (e.g., hydrazone bond) [31-33]. The self-assembly micelles were prepared from PEG- $b$ poly(aspartate-hydrazone-DOX) copolymers obtained after the chemical conjugation of DOX to the side chain of PEG-b-poly(aspartate) copolymers via an acid-labile hydrazone linker. Such $\mathrm{pH}$-sensitive 
polymeric micelles hold the drugs at physiological conditions ( $\mathrm{pH} 7.4)$, but release active DOX at a low pH (pH 5.0). Similarly, Hruby et al. reported a pH-sensitive polymeric micelle with a hydrazone bond between the polymer and DOX [34]. After the incubation of micelles in buffers at $37^{\circ} \mathrm{C}$, DOX was released more rapidly at pH 5.0 (43\% DOX released within 24 hours) than at pH 7.4 (16\% DOX released within 24 hours). Despite this $\mathrm{pH}$-selectivity, the pharmaceutical uses of hydrazone bonds may prove somewhat limited, as the chemical cleavage of the hydrazone bond can also release inactive DOX fragments.

Recently, our group designed a novel mode of drug delivery using polyHis (Mw 5K)- $b$-PEG (Mw $2 \mathrm{~K}$ ) and PLLA (Mw 3K)-b-PEG (Mw 2K)-b-polyHis (Mw 2K)-TAT peptide [TAT: transactivator of transcription, Gly-Cys-(Gly)3-Tyr-Gly-Arg-(Lys)2-(Arg)2-Gln-(Arg)3]] [35-36]. It is known that the TAT peptide, a non-specific cell penetrating peptide, is derived from human immunodeficiency viruses types 1 and 2 (HIV-1 and HIV-2), which have been reported to facilitate the rapid translocation of various macromolecules into mammalian cells [37]. In this study, we utilized both copolymers for the preparation of a self-assembled mixed micelle consisting of a hydrophobic core [PLLA and polyHis (Mw $5 \mathrm{~K}$ )] and a hydrophilic shell (PEG and TAT peptide) at physiological pH. Here, the shorter polyHis block (Mw $2 \mathrm{~K}$ ) within the PLLA-b-PEG-b-polyHis-TAT is self-assembled at the interface between the hydrophobic core and the hydrophilic PEG shell, owing to the presence of the hydrophilic PEG and TAT peptides on both sides of polyHis (Mw $2 \mathrm{~K}$ ). In particular, the interfacial polyHis (Mw 2 $\mathrm{K})$ induced the bending of the PEG chain within the PLLA- $b$-PEG- $b$-polyHis-TAT, resulting in the burial of the TAT peptide coupled with polyHis (Mw $2 \mathrm{~K}$ ) within the stretched PEG shell derived from the polyHis-b-PEG block copolymer. However, as the $\mathrm{pH}$ is lowered below $\mathrm{pH} 7.0$, the degree of ionization of the interfacial polyHis ( $\mathrm{Mw} 2 \mathrm{~K}$ ) block increases. This weakens the hydrophobic interaction between polyHis (Mw $2 \mathrm{~K}$ ) and the micellar core, resulting in the stretching of the bended PEG chain and exposing the TAT peptide from the PEG shell via this pop-up mechanism. This process may enhance the cellular uptake of drug carriers via TAT peptide-mediated endocytosis. Furthermore, when the $\mathrm{pH}$ is lowered further $(\mathrm{pH}<6.5$; close to endosomal $\mathrm{pH})$, the micellar core consisting of polyHis (Mw $5 \mathrm{~K}$ ) and PLLA blocks is destabilized in the endosomal compartments, resulting in the disruption of the endosomal membrane as a result of the proton sponge effect of polyHis (Mw $5 \mathrm{~K}$ ) $[35,36]$. This process was demonstrated to increase drug concentration in tumor cells and improve drug therapeutics.

On the other hand, a virus-mimetic nanogel (VM nanogel) was developed for the modulation of cytosolic drug concentration in a controlled manner. VM nanogel consists of a hydrophobic core [poly(His-co-Phenylalanine)] and two layers of hydrophilic shells [PEG and bovine serum albumin (BSA) (Figure 2) [38]. One PEG end is multi-linked to BSA, and the other end is linked to the core polymer, which forms a capsid-like outer shell. At low $\mathrm{pH}$, the core of this system is swelled by the ionization of polyHis, whereas at high $\mathrm{pH}$, the core shrinks. In this regard, the DOX release rate can be accelerated from swollen nanogels at endosomal $\mathrm{pH}$ (e.g., $\mathrm{pH}$ 6.4), whereas the DOX release rate was reduced from the shrunk nanogels at cytosolic $\mathrm{pH}$ (e.g., $\mathrm{pH}$ 7.4-6.8). Moreover, the expansion of the volume of VM nanogels and the proton sponge effect of polyHis at endosomal $\mathrm{pH}$ are assumed to provide profound endosomal escape properties. These functionalities of VM nanogel allow for the translocation of drugs or nanogels from the endosomes to the cytoplasm, where the VM nanogels 
rapidly shrink back to their original size under a more neutral local $\mathrm{pH}$. This shrinkage is followed by the minimization of the drug release rate. It is important that anticancer drugs released under the stimulus of endosomal $\mathrm{pH}$ diffuse into the nucleus, ultimately leading to cell apoptosis. Furthermore, apoptosized cell bodies will release the shrunk nanogels (still active) for subsequent infection and action in other neighboring cells. This VM nanogel system was identified as a 'serial killer' of tumor cells [38].

Figure 2. Virus-mimetic nanogel system. The virus-like infectious nanogel consists of a hydrophobic core [poly(His-co-Phe)] and two layers of hydrophilic shells [(PEG and BSA)]. Reproduced with permission from [38].
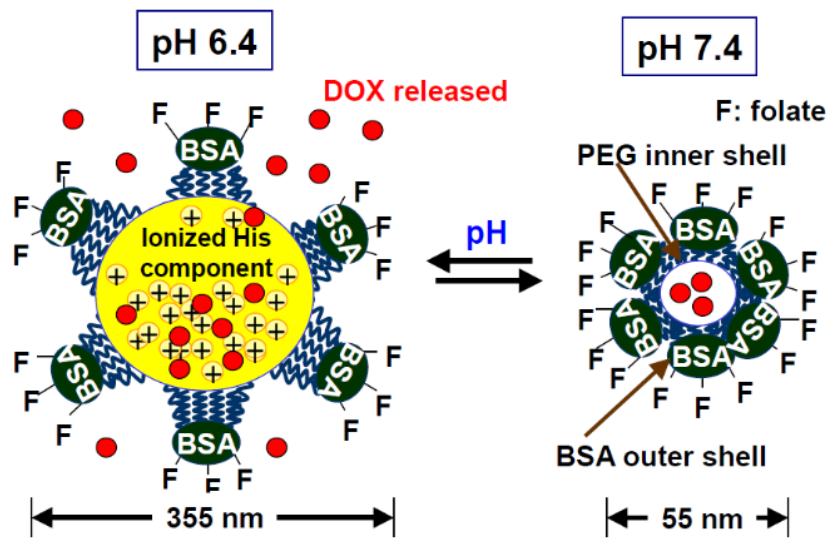

\subsubsection{Protein drug delivery}

Kataoka's group introduced a charge conversion polymer, specifically PEG- $b$-poly(N'-citraconyl-2aminoethly-aspartamide) [PEG- $b$-pAsp(EDA-Cit)], in order to fabricate a novel protein drug carrier for cytosolic delivery $[39,40]$. The polyionic complex (PIC) was prepared in an aqueous solution via the electrostatic interaction between a charge conversion polymer and a cationic protein (lysozyme). Interestingly, PEG-b-pAsp(EDA-Cit) has a pH-labile component (i.e., citraconic amide) that is degradable under endosomal acidic $\mathrm{pH}$ conditions. At a $\mathrm{pH}$ of 5.5, the citraconyl-2-aminoethyl group is transferred to the free 2-aminoethyl group, presenting the charge switching from negative (citraconyl-2aminoethyl group) to positive (2-aminoethyl group). This change in electrical charge accelerates the protein release rate at $\mathrm{pH} 5.5$ by virtue of the electro-repulsive force between the positively charged 2aminoethyl group and the lysozyme (Figure 3). Furthermore, PIC prepared from PEG- $b$-poly(N,N'-2aminoethyl-2-aminoethyl aspartamide) [PEG- $b$-pAsp(DET)] and cytocrome c-citraconic acid (Cyt-Cit) or cytocrome c-cis-aconitic (Cyt-Aco) demonstrated pH-stimulated protein (Cyt) release, depending on the chemical cleavage of Cyt-Cit or Cyt-Aco to Cyt at pH 5.5 (close to endosomal $\mathrm{pH}$ ). In particular, Cyt that is chemically free from Cit or Aco absorbs protons, which may cause swelling or burst the endosomes, as a result of the proton sponge effect. This system consequently resulted in high Cyt concentration in the cytoplasm, as evaluated from the in vitro cell test. Similarly, Liu et al. synthesized poly(allylamine)-citraconic acid for the preparation of a polyelectrolyte multi-layer that responds to endosomal $\mathrm{pH}$ ( $\mathrm{pH}$ 5.0) [41]. The multi-layer film system allowed for the triggering of protein release at $\mathrm{pH}$ 5.0. These systems are indeed comparable with that 
of a charge conversion polymer modified with 2,3-dimethylmaleic acid (DMA). Lee et al. suggested that other polymeric nanocomplexes, consisting of cationic protein (lysozyme) and glycol chitosan (GC) grafted with DMA (GC-g-DMA), might exist. Unlike the work of Kataoka's group, the GC-g-DMA/lysozyme complex disintegrated rapidly at $\mathrm{pH} 6.8$ (close to tumor extracellular $\mathrm{pH}$ ), owing to the chemical separation of DMA from GC-g-DMA [47,48]. This complex inhibits protein release at $\mathrm{pH} 7.4$ and promotes protein release at $\mathrm{pH} 6.8$.

Figure 3. Schematic representation of the actions of the charge-converting nanocomplex at endosomal $\mathrm{pH}$.

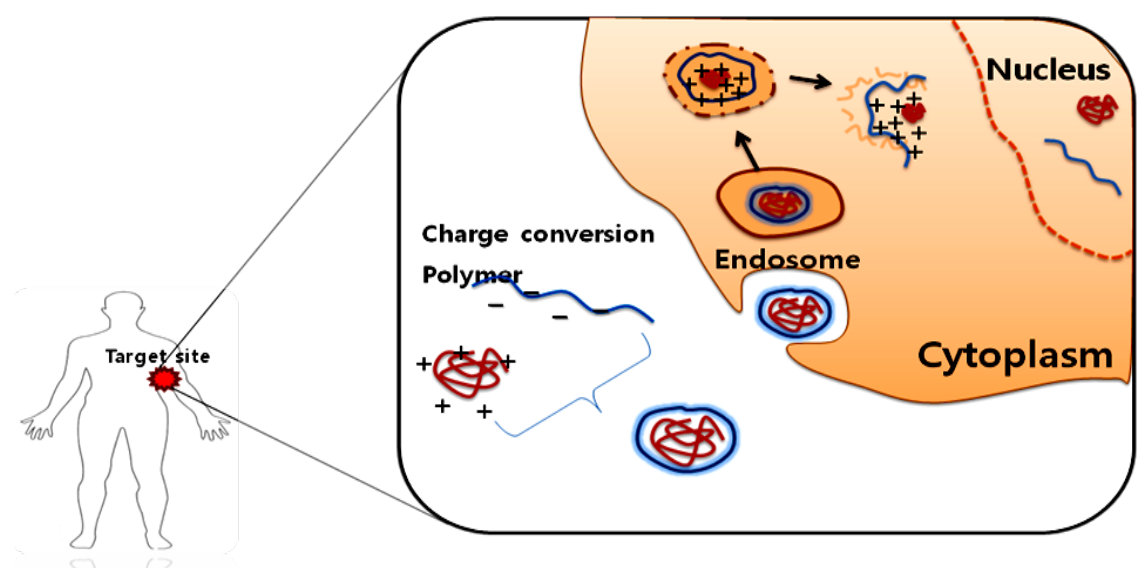

On the other hand, hydrophobically-modified poly( $\gamma$-glutamic acid) ( $\gamma$-PGA) nanoparticles have been previously utilized for cytosolic protein delivery [44]. The formation of the helix structure of $\gamma$-PGA at pH 5.5 serves as a hemolytic activator, providing the ability to escape from the endosomes and to deliver protein drugs to the cytoplasm.

Tada et al. utilized carbonate apatite nanoparticles for the transport of proteins to the cytoplasm [45]. This nanoparticle was prepared via the electrostatic interaction of BSA with the positively charged surfaces of carbonate apatite particles at a $\mathrm{pH}$ of 7.4. Interestingly, the high water solubility of carbonate apatite particles at endosomal $\mathrm{pH}$ values $(\mathrm{pH}$ 5.0) induced the accelerated release of the electrostatically associated proteins into the cytoplasm. Actually, the fluorescence-labeled BSA incorporated into BSA/carbonate apatite complexes was observed, via confocal microscopy, to be effectively delivered into the cytoplasm of HeLa cells.

\subsection{Enzyme-Activating Systems}

Cells harbor a variety of enzymes in the intracellular compartment, including endosomes, lysosomes, and the cytoplasm. These enzymes have recently been utilized as specific signals for triggered drug release from drug carriers [55-75]. For example, the labile linkers (such as disulfide bonds, ester bonds, and certain peptide spacers) in drug carriers are readily cleaved via certain enzymatic reactions. These linkers cleaved by specific enzymes in the target sites (e.g., lysosome, endosome, cytoplasm) signaled stimulated drug release by employing the strategy of destabilizing the drug carriers.

Kopecek's group synthesized a non-toxic and non-immunogenic $N$-(2-hydroxypropy1) methacrylamide (HPMA) copolymer grafted with anticancer drugs (e.g., DOX, mesochlorin e6 
monoethylenediamine, geldanamycin (GDM), gemcitabine) via a lysosomally-degradable tetrapeptide linker (Gly-Phe-leu-Gly, GFLG) [60-72]. Here, GFLG is a specific area that can be cleaved by a lysosomal enzymatic system, such as cathepsin B and cysteine proteinase. It has been determined that lysosomes are the cells' garbage disposal system and harbor a variety of enzymes, including protease, nuclease, etc. [83]. The activities of these lysosomal enzymes have been previously employed in the development of a novel enzyme-degradable pro-drug (polymer-drug conjugate) with reduced toxic effects for normal tissue and with increased therapeutic efficacy for tumor sites. However, enzymatic metabolism may also prove effective with the free drug, which will significantly attenuate the therapeutic activity of the drug.

Wang et al. synthesized poly( $\varepsilon$-caprolactone) (PCL)-b-poly(ethyl ethylene phosphate) (PEET) with a disulfide-linker (-SS-) for intracellular drug delivery [84]. An anticancer drug (DOX) and PCL- $b$-PEET were dialyzed in order to construct the self-assembled polymeric micelles. The resultant micelles include a disulfide linker sensitive to the reduction reaction in cells. Reduction and oxidation (redox reactions) are chemical phenomena in which certain molecules gain or lose electrons [85-88]. In the majority of mammalian cells, intracellular compartments, such as cytoplasm and nuclei, favor more reduced forms of certain molecules, unlike the extracellular milieu, in which the oxidized counterpart forms are favored [85-88]. For example, reduced glutathione (GSH) was detected at $\sim 20 \mu \mathrm{M}$ in the plasma and $\sim 10 \mathrm{mM}$ in the cytoplasm [87]. Furthermore, the following preference order of GSH over oxidized glutathione (GSSG) in cells was observed: mitochondria > nuclei > cytoplasm > extracellular milieu [88]. This selectivity for each organelle may prove useful in the design of a site-specific drug delivery system sensitive to the redox reaction. As a consequence, DOXloaded micelles with disulfide-linkers were destabilized in the cytoplasm as a result of the reduction reaction for the disulfide-linker, thus allowing for the release of DOX from the micelles [84].

Minko et al. previously prepared a poly(amidoamine) (PAMAM) dendrimer conjugated with anticancer drug (paclitaxel, PTX) via a succinic acid (SA) spacer [89]. Both sides of the SA spacer coupled with PAMAM or PTX include two ester bonds that can be cleaved by esterase. Thus, active drug or metabolized drugs (by lysosomal enzymes) may be released simultaneously from the dendrimer, resulting from the enzymatic degradation of the SA spacer. Similarly, Haag et al. designed a non-toxic, water-soluble, non-immunogenic polyglycerol (PG) dendrimer conjugated with DOX and methotrexate (MTX) via the dipeptide Phe-Lys or the tripeptide Ala-Phe-Lys linker [90]. These peptide linkers were employed as the substrates for lysosomal cathepsin B. They facilitated the release of DOX or MTX from the dendrimers enzymatically degraded in tumor cells. In addition, Shabat et al. demonstrated the synthesis of a trimeric pro-drug, which contains three anticancer drugs (such as DOX, etoposide, and camptothecin) linked to certain enzymatic substrates [91]. After the enzymatic degradation of substrates by the catalytic antibody 38C2 in human MOLT-3 leukemia cells, three anticancer drugs were simultaneously released.

Nakagawa et al. employed $\gamma$-PGA-based nanoparticles ( $\gamma$-PGA NPs) with L-phenylalanine ethyl ester (L-PAE) for cytosolic protein delivery [92]. However, the $\gamma$-PGA NPs encapsulating ovalbumin (OVA) require the enzymatic degradation of L-PAE for the release of OVA. It appeared that the protein drugs released from this carrier may also be degraded by a variety of enzymatic metabolisms. 


\subsection{Temperature-Activating Systems}

Thermo-responsive polymeric nanocarriers for use in anticancer drug delivery have been previously fabricated from a variety of polymer architectures consisting of temperature-sensitive blocks, hydrophilic blocks, and hydrophobic blocks [93-108]. Here, poly(N-isopropylacrylamide) (PNIPAAm), Pluronic ${ }^{\circledR}$ F-127 and poly(organophophazenes) have been used, principally as temperature-sensitive polymers. Recently, drug release kinetics have been controlled effectively with respect to the use of these polymers, even within the cytoplasm [93-97]. Unlike the heat shock (hyperthermia) applied to tumor cells for anticancer therapy [105-108], cold-shock using cooling processes resulted in an expansion of the volume of thermo-responsive drug carriers [93-97], thereby enabling the cytosolic translocation of drug or drug carriers from physically burst endosomes. Park's study group prepared Pluronic ${ }^{\circledR}$ F-127 nanocapsules via the cross-linking reaction of poly(ethylene imine) (PEI) (or heparin) and Pluronic ${ }^{\circledR}$ F-127 [93-95]. These nanocapsules evidenced a volume expansion over a temperature range of $24-33{ }^{\circ} \mathrm{C}: \sim 100 \mathrm{~nm}$ size at $37{ }^{\circ} \mathrm{C}$ and $\sim 350 \mathrm{~nm}$ size at $25{ }^{\circ} \mathrm{C}$. In particular, the reversible volume transition of these nanocapsules, in response to temperature, is attributable to the micellization or demicellization of Pluronic ${ }^{\circledR}$ F-127 within the nanocapsules, depending on the critical micelle temperature (CMT) (Figure 4) of Pluronic ${ }^{\circledR}$ F-127 [93-95]. Furthermore, they designed superexpandable nanogels upon cooling for thermally triggered tumor cell death [96]. The nanogels, consisting of oligo(L-lactic acid) (OLA)- $b$-PEG- $b$-poly(propylene oxide) (PPO)- $b$-PEG- $b$-OLA and PEG-grafted poly(L-lysine), evidenced a reversible volume transition from $\sim 150 \mathrm{~nm}$ at body temperature to $\sim 1.4 \mu \mathrm{m}$ at $15{ }^{\circ} \mathrm{C}$. Under cold shock conditions, HeLa cells treated with the nanogels evidenced a cell viability of $54.0 \pm 22.1 \%$, whereas those maintained at $37^{\circ} \mathrm{C}$ evidenced a cell viability of $92.2 \pm 7.2 \%$. The nanogel undergoing a nano- to micro-scale volume transition in response to temperature seemed to evoke necrotic cell death under cold shock conditions. Overall, these carriers are expected to prove beneficial in the future, with respect to achieving effective therapeutic results.

Additionally, Okano's study group has reported that PNIPAAm conjugated to dimethylaminoethyl methacrylate (DMAEMA) and butyl methacrylate (BMA) was insoluble at temperatures above $21{ }^{\circ} \mathrm{C}$ and was soluble at temperatures below $21^{\circ} \mathrm{C}$ [97]. The nanoparticles prepared using this polymer conjugate triggered drug release at temperatures below $21^{\circ} \mathrm{C}$, similar to what was observed with the cold shock effect.

Figure 4. Schematic diagram of Pluronic ${ }^{\circledR}$ F-127 nanocapsules. Reproduced with permission from reference [94].

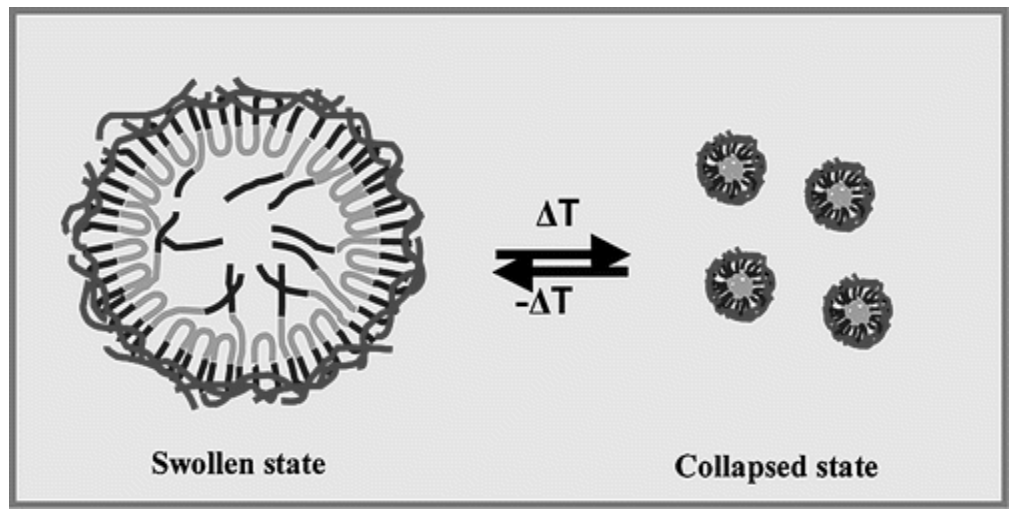




\section{Conclusions}

Nanoscale drug delivery systems have been extensively developed over the past few years. The evolution of nanotechnology has created significant changes in drug delivery systems. A great deal of attention has been focused on the development of smart drug carrier systems that recognize the physicochemical or biological differences between non-targeted sites and targeted sites. Acidic $\mathrm{pH}$ in cells, specific enzymes in cells, and temperature effects for cells, have been investigated intensively and employed as crucial signals for the delivery of drugs to the cytoplasm. These recent studies are expected to usher in a new paradigm of improved drug therapeutics.

\section{Acknowledgements}

This work was supported by Basic Science Research Program through the National Research Foundation of Korea (NRF) funded by the Ministry of Education, Science and Technology (20090063870), by the Biogreen21 Program (Code\# PJ007186), Rural Development Administration, Republic of Korea, by a grant from the Fundamental R\&D Program for Core Technology of Materials funded by the Ministry of Knowledge Economy, Republic of Korea, and by the Research Grant funded by the Gyeonggi Regional Research Center (GRRC).

\section{References}

1. Torchilin, V.P. Drug targeting. Eur. J. Pharm. Sci. 2000, 11, 81-91.

2. Allen, T.M.; Cullis, P.R. Drug delivery systems: Entering the mainstream. Science 2004, 303, 1818-1822.

3. Peer, D.; Karp, J.M.; Hong, S.; Farokhzad, O.; Margalit, R.; Langer, R. Nanocarriers as an emerging platform for cancer therapy. Nat. Nanotechnol. 2007, 2, 751-760.

4. Lammers, T.; Hennink, W.E.; Storm, G. Tumour-targeted nanomedicines: Principles and practice. Br. J. Cancer 2008, 99, 392-397.

5. Davis, M.E.; Chen, Z.G.; Shin, D.M. Nanoparticle therapeutics: An emerging treatment modality for cancer. Nat. Rev. Drug Discov. 2008, 7, 771-782.

6. Zhang, Z.; Cao, W.; Jin, H.; Lovell, J.F.; Yang, M.; Ding, L.; Chen, J.; Corbin, I.; Luo, Q.; Zheng, G. Biomimetic nanocarrier for direct cytosolic drug delivery. Angew. Chem. Int. Ed. Engl. 2009, 48, 9171-9175.

7. Lu, Y.; Low, P.S. Folate-mediated delivery of macromolecular anticancer therapeutic agents. Adv. Drug Delivery Rev. 2002, 54, 675-693.

8. Sethuraman, V.A.; Bae, Y.H. TAT peptide-based micelle system for potential active targeting of anti-cancer agents to acidic solid tumors. J. Control. Release 2007, 118, 216-224.

9. Jabr-Milane, L.S.; van Vlerken, L.E.; Yadav, S.; Amiji, M.M. Multi-functional nanocarriers to overcome tumor drug resistance. Cancer Treat. Rev. 2008, 34, 592-602.

10. van Vlerken, L.E.; Vyas, T.K.; Amiji, M.M. Poly(ethylene glycol)-modified nanocarriers for tumor-targeted and intracellular delivery. Pharm. Res. 2007, 24, 1405-1414.

11. Nishiyama, N.; Kataoka, K. Current state, achievements, and future prospects of polymeric micelles as nanocarriers for drug and gene delivery. Pharmacol. Ther. 2006, 112, 630-648. 
12. Maeda, H.; Sawa, T.; Konno, T. Mechanism of tumor-targeted delivery of macromolecular drugs, including the EPR effect in solid tumor and clinical overview of the prototype polymeric drug SMANCS. J. Control. Release 2001, 74, 47-61.

13. Maeda, H.; Bharate, G.Y.; Daruwalla, J. Polymeric drugs for efficient tumor-targeted drug delivery based on EPR-effect. Eur. J. Pharm. Biopharm. 2009, 71, 409-419.

14. Maeda, H.; Wu, J.; Sawa, T.; Matsumura, Y.; Hori, K. Tumor vascular permeability and the EPR effect in macromolecular therapeutics: A review. J. Control. Release 2000, 64, 271-284.

15. Liu, H.; Moy, P.; Kim, S.; Xia, Y.; Rajasekaran, A.; Navarro, V.; Knudsen, B.; Bander, N.H. Monoclonal antibodies to the extracellular domain of prostate-specific membrane antigen also react with tumor vascular endothelium. Cancer Res. 1997, 57, 3629-3634.

16. Juweid, M.; Neumann, R.; Paik, C.; Perez-Bacete, M.J.; Sato, J.; van Osdol, W.; Weinstein, J.N. Micropharmacology of monoclonal antibodies in solid tumors: Direct experimental evidence for a binding site barrier. Cancer Res. 1992, 52, 5144-5153.

17. Sudimack, J.; Lee, R.J. Targeted drug delivery via the folate receptor. Adv. Drug Delivery Rev. 2000, 41, 147-162.

18. Green, M.C.; Murray, J.L.; Hortobagyi, G.N. Monoclonal antibody therapy for solid tumors. Cancer Treat. Rev. 2000, 26, 269-286.

19. Trowbridge, I.S.; Lopez, F. Monoclonal antibody to transferrin receptor blocks transferrin binding and inhibits human tumor cell growth in vitro. Proc. Natl. Acad. Sci. USA 1982, 79, 1175-1179.

20. Lee, E.S.; Shin, H.J.; Na, K.; Bae, Y.H. Poly(L-histidine)-PEG block copolymer micelles and pH-induced destabilization. J. Control. Release 2003, 90, 363-374.

21. Na, K.; Lee, K.H.; Bae, Y.H. pH-sensitivity and pH-dependent interior structural change of self-assembled hydrogel nanoparticles of pullulan acetate/oligo-sulfonamide conjugate. $J$. Control. Release 2004, 97, 513-525.

22. Tolcher, A.W.; Mita, M.; Meropol, N.J.; von Mehren, M.; Patnaik, A.; Padavic, K.; Hill, M.; Mays, T.; McCoy, T.; Fox, N.L.; Halpern, W.; Corey, A.; Cohen, R.B. Phase I pharmacokinetic and biologic correlative study of mapatumumab, a fully human monoclonal antibody with agonist activity to tumor necrosis factor-related apoptosis-inducing ligand receptor-1. J. Clin. Oncol. 2007, 25, 1390-1395.

23. Oosterwijk, E.; Bander, N.H.; Divgi, C.R.; Welt, S.; Wakka, J.C.; Finn, R.D.; Carswell, E.A.; Larson, S.M.; Warnaar, S.O.; Fleuren, G.J. Antibody localization in human renal cell carcinoma: A phase I study of monoclonal antibody G250. J. Clin. Oncol. 1993, 11, 738-750.

24. Konda, S.D.; Aref, M.; Brechbiel, M.; Wiener, E.C. Development of a tumor-targeting MR contrast agent using the high-affinity folate receptor: Work in progress. Invest. Radiol. 2000, 35, 50-57.

25. Gao, X.; Cui, Y.; Levenson, R.M.; Chung, L.W.K.; Nie, S. In vivo cancer targeting and imaging with semiconductor quantum dots. Nat. Biotechnol. 2004, 22, 969-976.

26. Oh, K.T.; Baik, H.J.; Lee, A.H.; Oh, Y.T.; Youn, Y.S.; Lee, E.S. The reversal of drug-resistance in tumors using a drug-carrying nanoparticular system. Int. J. Mol. Sci. 2009, 10, 3776-3792.

27. Lee, E.S.; Shin, H.J.; Na, K.; Bae, Y.H. Poly(L-histidine)-PEG block copolymer micelles and pH-induced destabilization. J. Control. Release 2003, 90, 363-374. 
28. Lee, E.S.; Na, K.; Bae, Y.H. Doxorubicin loaded pH-sensitive polymeric micelles for reversal of resistant MCF-7 tumor. J. Control. Release 2005, 103, 405-418.

29. Lee, E.S.; Na, K.; Bae, Y.H. Polymeric micelle for tumor $\mathrm{pH}$ and folate-mediated targeting. $J$. Control. Release 2003, 91, 103-113.

30. Kang, H.C.; Lee, M.; Bae, Y.H. Polymeric gene carriers. Crit. Rev. Eukaryot. Gene Expr. 2005, 15, 317-342.

31. Bae, Y.; Fukushima, S.; Harada, A.; Kataoka, K. Design of environment-sensitive supramolecular assemblies for intracellular drug delivery: Polymeric micelles that are responsive to intracellular pH change. Angew. Chem. Int. Ed. Engl. 2003, 42, 4640-4643.

32. Bae, Y.; Nishiyama, N.; Fukushima, S.; Koyama, H.; Yasuhiro, M.; Kataoka, K. Preparation and biological characterization of polymeric micelle drug carriers with intracellular $\mathrm{pH}$-triggered drug release property: Tumor permeability, controlled subcellular drug distribution, and enhanced in vivo antitumor efficacy. Bioconjugate Chem. 2005, 16, 122-130.

33. Nishiyama, N.; Bae, Y.; Miyata, K.; Fukushima, S.; Kataoka, K. Smart polymeric micelles for gene and drug delivery. Drug Discov. Today Technol. 2005, 2, 21-26.

34. Hruby, M.; Konak, C.; Ulbrich, K. Polymeric micellar pH-sensitive drug delivery system for doxorubicin. J. Control. Release 2005, 103, 137-148.

35. Lee, E.S.; Gao, Z.; Bae, Y.H. Recent progress in tumor $\mathrm{pH}$ targeting nanotechnology. J. Control. Release 2008, 132, 164-170.

36. Lee, E.S.; Gao, Z.; Kim, D.; Park, K.; Kwon, I.C.; Bae, Y.H. Super pH-sensitive multifunctional polymeric micelle for tumor $\mathrm{pH}_{\mathrm{e}}$ specific TAT exposure and multidrug resistance. J. Control. Release 2008, 129, 228-236.

37. Eguchi, A.; Akuta, T.; Okuyama, H.; Senda, T.; Yokoi, H.; Inokuchi, H.; Fujita, S.; Hayakawa, T.; Takeda, K.; Hasegawa, M.; Nakanishi, M. Protein transduction domain of HIV-1 Tat protein promotes efficient delivery of DNA into mammalian cells. J. Biol. Chem. 2001, 276, 26204-26210.

38. Lee, E.S.; Kim, D.; Youn, Y.S.; Oh, K.T.; Bae, Y.H. A novel virus-mimetic nanogel vehicle. Angew. Chem. Int. Ed. Engl. 2008, 47, 2418-2421.

39. Lee, Y.; Fukushima, S.; Bae, Y.; Hiki, S.; Ishii, T.; Kataoka, K. A protein nanocarrier from charge-conversion polymer in response to endosomal pH. J. Am. Chem. Soc. 2007, 129, 5362-5363.

40. Lee, Y.; Ishii, T.; Cabral, H.; Kim, H.J.; Seo, J.H.; Nishiyama, N.; Oshima, H.; Osada, K.; Kataoka, K. Charge-conversional polyionic complex micelles-efficient nanocarriers for protein delivery into cytoplasm. Angew. Chem. Int. Ed. Engl. 2009, 48, 5309-5312.

41. Liu, X.; Zhang, J.; Lynn, D.M. Polyelectrolyte multilayers fabricated from 'charge-shifting' anionic polymers: A new approach to controlled film disruption and the release of cationic agents from surfaces. Soft Matter 2008, 4, 1688-1695.

42. Lee, B.R.; Oh, K.T.; Baik, H.J.; Youn, Y.S.; Lee, E.S. A charge-switched nano-sized polymeric carrier for protein delivery. Int. J. Pharm. 2010. 392, 78-82.

43. Oh, K.T.; Kim, D.; You, H.H.; Ahn, Y.S.; Lee, E.S. pH-sensitive properties of surface chargeswitched multifunctional polymeric micelle. Int. J. Pharm. 2009, 376, 134-140.

44. Akagi, T.; Kim, H.; Akashi, M. pH-dependent disruption of erythrocyte membrane by amphiphilic poly(amino acid) nanoparticles. J. Biomater. Sci., Polym. Ed. 2010, 21, 315-328. 
45. Tada, S.; Chowdhury, E.H.; Cho, C.S.; Akaike, T. pH-sensitive carbonate apatite as an intracellular protein transporter. Biomaterials 2010, 31, 1453-1459.

46. Kim, G.M.; Bae, Y.H.; Jo, W.H. pH-induced micelle formation of poly(histidine-co-phenylalanine)block-poly(ethylene glycol) in Aqueous Media. Macromol. Biosci. 2005, 5, 1118-1124.

47. Dufresne, M.H.; Garrec, D.L.; Sant, V.; Leroux, J.C.; Ranger, M. Preparation and characterization of water-soluble $\mathrm{pH}$-sensitive nanocarriersfor drug delivery. Int. J. Pharm. 2004, 277, 81-90.

48. Bae, Y.; Jang, W.D.; Nishiyama, N.; Fukushima, S.; Kataoka, K. Multifunctional polymeric micelles with folate-mediated cancer cell targeting and $\mathrm{pH}$-triggered drug releasing properties for active intracellular drug delivery. Mol. Biosyst. 2005, 1, 242-250.

49. Shim, W.S.; Kim, J.H.; Kim, K.; Kim, Y.S.; Park, R.W.; Kim, I.S.; Kwon, I.C.; Lee, D.S. $\mathrm{pH}$ - and temperature- sensitive, injectable, biodegradable block copolymer hydrogels as carriers for paclitaxel. Int. J. Pharm. 2007, 331, 11-18.

50. Kim, Y.H.; Bae, Y.H.; Kim, S.W. pH/temperature-sensitive polymers for macromolecular drug loading and release. J. Control. Release 1994, 28, 143-152.

51. Lee, R.J.; Wang, S.; Turk, M.J.; Low, P.S. The effects of $\mathrm{pH}$ and intraliposomal buffer strength on the rate of liposome content release and intracellular drug delivery. Biosci. Rep. 1998, 18, 69-78.

52. Gerasimov, O.V.; Boomer, J.A.; Qualls, M.M.; Thompson, D.H. Cytosolic drug delivery using pH- and light- sensitive liposomes. Adv. Drug Delivery Rev. 1999, 38, 317-338.

53. Sharma, A.; Sharma, U.S. Liposomes in drug delivery: Progress and limitations. Int. J. Pharm. 1997, 154, 123-140.

54. Lee, K.D.; Oh, Y.K.; Portnoy, D.A.; Swanson, J.A. Delivery of macromolecules into cytosol using liposomes containing hemolysin from Listeria monocytogenes. J. Biol. Chem. 1996, 271, 7249-7252.

55. Samad, A.; Sultana, Y.; Aqil, M. Liposomal drug delivery systems: An update review. Curr. Drug Delivery 2007, 4, 297-305.

56. Obata, Y.; Tajima, S.; Takeoka, S. Evaluation of pH-responsive liposomes containing amino acid-based zwitterionic lipids for improving intracellular drug delivery in vitro and in vivo. J. Control. Release 2010, 142, 267-276.

57. Leroux, J.; Roux, E.; Le Garrec, D.; Hong, K.; Drummond, D.C. N-isopropylacrylamide copolymers for the preparation of $\mathrm{pH}$-sensitive liposomes and polymeric micelles. J. Control. Release 2001, 72, 71-84.

58. Shi, G.; Guo, W.; Stephenson, S.M.; Lee, R.J. Efficient intracellular drug and gene delivery using folate receptor-targeted $\mathrm{pH}$-sensitive liposomes composed of cationic/anionic lipid combinations. J. Control. Release 2002, 80, 309-319.

59. Tachibana, R.; Harashima, H.; Shono, M.; Azumano, M.; Niwa, M.; Futaki, S.; Kiwada, H. Intracellular regulation of macromolecules using $\mathrm{pH}$-sensitive liposomes and nuclear localization signal: Qualitative and quantitative evaluation of intracellular trafficking. Biochem. Biophys. Res. Commun. 1998, 251, 538-544.

60. Tijerina, M.; Kopeckova, P.; Kopecek, J. Correlation of subcellular compartmentalization of HPMA copolymer-Mce6 conjugates with chemotherapeutic activity in human ovarian carcinoma cells. Pharm. Res. 2003, 20, 728-737. 
61. Kopecek, J.; Kopeckova, P.; Minko, T.; Lu, Z.R.; Peterson, C.M. Water soluble polymers in tumor targeted delivery. J. Control. Release 2001, 74, 147-158.

62. Kasuya, Y.; Lu, Z.R.; Kopeckova, P.; Minko, T.; Tabibi, S.E.; Kopecek. J. Synthesis and characterization of HPMA copolymer-aminopropylgeldanamycin conjugates. J. Control. Release 2001, 74, 203-211.

63. Zamai, M.; VandeVen, M.; Farao, M.; Gratton, E.; Ghiglieri, A.; Castelli, M.G.; Fontana, E.; D'Argy, R.; Fiorino, A.; Pesenti, E.; Suarato, A.; Caiolfa, V.R. Camptothecin poly[n-(2hydroxypropyl) methacrylamide] copolymers in antitopoisomerase-I tumor therapy: Intratumor release and antitumor efficacy. Mol. Cancer. Ther. 2003, 2, 29-40.

64. Vasey, P.A.; Kaye, S.B.; Morrison, R.; Twelves, C.; Wilson, P.; Duncan, R.; Thomson, A.H.; Murray, L.S.; Hilditch, T.E.; Murray, T.; Burtles, S.; Fraier, D.; Frigerio, E.; Cassidy, J. Phase I clinical and pharmacokinetic study of PK1 [N-(2-Hydroxypropyl)methacrylamide copolymer doxorubicin]: First member of a new class of chemotherapeutic agents-drug-polymer conjugates. Clin. Cancer Res. 1999, 5, 83-94.

65. Lammers, T.; Subr, V.; Peschke, P.; Kühnlein, R.; Hennink, W.E.; Ulbrich, K.; Kiessling, F.; Heilmann, M.; Debus, J.; Huber, P.E.; et al. Image-guided and passively tumour-targeted polymeric nanomedicines for radiochemotherapy. Br. J. Cancer 2008, 99, 900-910.

66. Lammers, T.; Subr, V.; Ulbrich, K.; Peschke, P.; Huber, P.E.; Hennink, W.E.; Storm, G. Simultaneous delivery of doxorubicin and gemcitabine to tumors in vivo using prototypic polymeric drug carriers. Biomaterials 2009, 30, 3466-3475.

67. Duncan, R. Designing polymer conjugates as lysosomotropic nanomedicines. Biochem. Soc. Trans. 2007, 35, 56-60.

68. Duncan, R. Development of HPMA copolymer-anticancer conjugates: Clinical experience and lessons learnt. Adv. Drug Deliv. Rev. 2009, 61, 1131-1148.

69. Etrych, T.; Chytil, P.; Jelinkova, M.; Rihova, B.; Ulbrich, K. Synthesis of HPMA copolymers containing doxorubicin bound via a hydrazone linkage. effect of spacer on drug release and in vitro cytotoxicity. Macromol. Biosci. 2002, 2, 43-52.

70. Christie, R.J.; Grainger, D.W. Design strategies to improve soluble macromolecular delivery constructs. Adv. Drug Delivery Rev. 2003, 55, 421-437.

71. Meers, P. Enzyme-activated targeting of liposomes. Adv. Drug Delivery Rev. 2001, 53, 265-272.

72. Hongrapipat, J.; Kopeckova, P.; Prakongpan, S.; Kopecek, J. Enhanced antitumor activity of combinations of free and HPMA copolymer-bound drugs. Int. J. Pharm. 2008, 53, 259-270.

73. Duncan, R.; Gac-Breton, S.; Keane, R.; Musila, R.; Sat, Y.N.; Satchi, R.; Searle, F. Polymer-drug conjugates, PDEPT and PELT: Basic principles for design and transfer from the laboratory to clinic. J. Control. Release 2001, 74, 135-146.

74. Hongrapipat, J.; Kopeckova, P.; Liu, J.; Prakongpan, S.; Kopecek, J. Combination chemotherapy and photodynamic therapy with Fab' fragment targeted HPMA copolymer conjugates in human ovarian carcinoma cells. Mol. Pharm. 2008, 5, 696-709.

75. Galande, A.K.; Hilderbrand, S.A.; Weissleder, R.; Tung, C.H. Enzyme-targeted fluorescent imaging probes on a multiple antigenic peptide core. J. Med. Chem. 2006, 49, 4715-4720.

76. Lee, H.; Mok, H.; Lee, S.; Oh, Y.; Park, T.G. Target-specific intracellular delivery of siRNA using degradable hyaluronic acid nanogels. J. Control. Release 2007, 119, 245-252. 
77. Cerritelli, S.; Velluto, D.; Hubbell, J.A. PEG-SS-PPS: Reduction-sensitive disulfide block copolymer vesicles for intracellular drug delivery. Biomacromolecules 2007, 8, 1966-1972.

78. Dalkara, D.; Chandrashekhar, C.; Zuber, G. Intracellular protein delivery with a dimerizable amphiphile for improved complex stability and prolonged protein release in the cytoplasm of adherent cell lines. J. Control. Release 2006, 116, 353-359.

79. Sun, H.; Guo, B.; Li, X.; Cheng, R.; Meng, F.; Liu, H.; Zhong, Z. Shell-sheddable micelles based on dextran-SS-poly( $\varepsilon$-caprolactone) diblock copolymer for efficient intracellular release of doxorubicin. Biomacromolecules 2010, 11, 848-854.

80. Ganta, S.; Devalapally, H.; Shahiwala, A.; Amiji, M. A review of stimuli-responsive nanocarriers for drug and gene delivery. J. Control. Release 2008, 126, 187-204.

81. Navath, R.S.; Wang, B.; Kannan, S.; Romero, R.; Kannan, R.M. Stimuli-responsive star poly(ethylene glycol) drug conjugates for improved intracellular delivery of the drug in neuroinflammation. J. Control. Release 2010, 142, 447-456

82. Oishi, M.; Hayama, T.; Akiyama, Y.; Takae, S.; Harada, A.; Yamasaki, Y.; Nagatsugi, F.; Sasaki, S.; Nagasaki, Y.; Kataoka, K. Supramolecular assemblies for the cytoplasmic delivery of antisense oligodeoxynucleotide: Polyion complex (PIC) micelles based on poly(ethylene glycol)SS-oligodeoxynucleotide conjugate. Biomacromolecules 2005, 6, 2449-2454.

83. Tappel, A. Lysosomal and prostasomal hydrolytic enzymes and redox processes and initiation of prostate cancer. Med. Hypotheses 2005, 64, 1170-1172.

84. Tang, L.; Wang, Y.; Li, Y.; Du, J.; Wang, J. Shell-detachable micelles based on disulfide-linked block copolymer as potential carrier for intracellular drug delivery. Bioconjugate Chem. 2009, 20, 1095-1099.

85. Saito, G.; Swanson, J.A.; Lee, K.D. Drug delivery strategy utilizing conjugation via reversible disulfide linkages: Role and site of cellular reducing activities. Adv. Drug Delivery Rev. 2003, 55, 199-215.

86. Calderon, M.; Quadir, M.A.; Strumia, M.; Haag, R. Functional dendritic polymer architectures as stimuli-responsive nanocarriers. Biochimie 2010, doi: 10.1016/j.biochi.2010.02.017.

87. Wu, G.; Fang, Y.Z.; Yang, S.; Lupton, J.R.; Turner, N.D. Glutathione metabolism and its implications for health. J. Nutr. 2004, 134, 489-492.

88. Hansen, J.M.; Go, Y.M.; Jones, D.P. Nuclear and mitochondrial compartmentation of oxidative stress and redox signaling. Annu. Rev. Pharmacol. Toxicol. 2006, 46, 215-234.

89. Khandare, J.J.; Jayant, S.; Singh, A.; Chandna, P.; Wang, Y.; Vorsa, N.; Minko, T. Dendrimer versus linear conjugate: Influence of polymeric architecture on the delivery and anticancer effect of paclitaxel. Bioconjugate Chem. 2006, 17, 1464-1472.

90. Calderón, M.; Graeser, R.; Kratz, F.; Haag, R. Development of enzymatically cleavable prodrugs derived from dendritic polyglycerol. Bioorg. Med. Chem. Lett. 2009, 19, 3725-3728.

91. Haba, K.; Popkov, M.; Shamis, M.; Lerner, R.A.; Barbas, C.F., III; Shabat, D. Single-triggered trimeric prodrugs. Angew. Chem. Int. Ed. 2005, 44, 716-720.

92. Yoshikawa, T.; Okada, N.; Oda, A.; Matsuo, K.; Matsuo, K.; Mukai, Y.; Yoshioka, Y.; Akagi, T.; Akashi, M.; Nakagawa, S. Development of amphiphilic gamma-PGA-nanoparticle based tumor vaccine: Potential of the nanoparticulate cytosolic protein delivery carrier. Biochem. Biophys. Res. Commun. 2008, 366, 408-413. 
93. Choi, S.H.; Lee, S.H.; Park, T.G. Temperature-sensitive pluronic/poly(ethylenimine) nanocapsules for thermally triggered disruption of intracellular endosomal compartment. Biomacromolecules 2006, 7, 1864-1870.

94. Choi, S.H.; Lee, J.H.; Choi, S.M.; Park, T.G. Thermally reversible Pluronic/Heparin nanocapsules exhibiting 1000-Fold volume transition. Langmuir 2006, 22, 1758-1762.

95. Lee, S.H.; Choi, S.H.; Kim, S.H.; Park, T.G. Thermally sensitive cationic polymer nanocapsules for specific cytosolic delivery and efficient gene silencing of siRNA: Welling induced physical disruption of endosome by cold shock. J. Control. Release 2008, 125, 25-32.

96. Lee, Y.; Park, S.Y.; Kim, C.; Park, T.G. Thermally triggered intracellular explosion of volume transition nanogels for necrotic cell death. J. Control. Release 2009, 135, 89-95.

97. Kurisawa, M.; Yokoyama, M.; Okano, T. Gene expression control by temperature with thermo-responsive polymeric gene carriers. J. Control. Release 2000, 69, 127-137.

98. Couffin-Hoarau, A.; Leroux, J. Report on the use of poly(organophosphazenes) for the design of stimuli-responsive vesicles. Biomacromolecules 2004, 5, 2082-2087.

99. Lavigne, M.D.; Pennadam, S.S.; Ellis, J.; Yater, L.L.; Alexander, C.; G’orecki1, D.C. Enhanced gene expression through temperature profile-induced variations in molecular architecture of thermoresponsive polymer vectors. J. Gene Med. 2007, 9, 44-54.

100. Liu, S.Q.; Wiradharma, N.; Gao, S.J.; Tong, Y.W.; Yang, Y.Y. Bio-functional micelles self-assembled from a folate-conjugated block copolymer for targeted intracellular delivery of anticancer drugs. Biomacromolecules 2007, 28, 1423-1433.

101. Kabanov, A.V.; Batrakova, E.V.; Alakhov, V.Y. Pluronic ${ }^{\circledR}$ block copolymers as novel polymer therapeutics for drug and gene delivery. J. Control. Release 2002, 82, 189-212.

102. Schmaljohann, D. Thermo- and $\mathrm{pH}$ - responsive polymers in drug delivery. Adv. Drug Delivery Rev. 2006, 58, 1655-1670.

103. Choi, S.H.; Lee, S.H.; Park, T.G. Temperature-sensitive pluronic/poly(ethylenimine) nanocapsules for thermally triggered disruption of intracellular endosomal compartment. Biomacromolecules 2006, 7, 1864-1870.

104. Chilkoti, A.; Dreher, M.R.; Meyer, D.E.; Raucher, D. Targeted drug delivery by thermally responsive polymers. Adv. Drug Delivery Rev. 2002, 54, 613-630.

105. Meyer, D.E.; Shin, B.C.; Kong, G.A.; Dewhirst, M.W.; Chilkoti, A. Drug targeting using thermally responsive polymers and local hyperthermia. J. Control. Release 2001, 74, 213-224.

106. Sticca, R.P.; Dach, B.W. Rationale for hyperthermia with intraoperative intraperitoneal chemotherapy agents. Surg. Oncol. Clin. N. Am. 2003, 12, 689-701.

107. Kong, G.; Braun, R.D.; Dewhirst, M.W. Hyperthermia enables tumor-specific nanoparticle delivery: Effect of particle size. Cancer Res. 2000, 60, 4440-4445.

108. Ponce, A.M.; Vujaskovic, Z.; Yuan, F.; Needham, D.; Dewhirst, M.W. Hyperthermia mediated liposomal drug delivery. Int. J. Hyperthermia 2006, 22, 205-213.

(C) 2010 by the authors; licensee MDPI, Basel, Switzerland. This article is an Open Access article distributed under the terms and conditions of the Creative Commons Attribution license (http://creativecommons.org/licenses/by/3.0/). 